\title{
Jugar con trampa. Taller de Arteterapia en el Centro de Día de Atención a Menores de Aldeas Infantiles SOS Granada
}

Recibido: $31 / 03 / 14$

Aceptado: 01/10/14

\author{
Manuela AVILÉS MARTOS \\ Universidad de Granada. \\ arteterapeuta@residenciaperpetuosocorro.org \\ Elizaberta LÓPEZ PÉREZ \\ Universidad de Granada. Dpto. de Escultura \\ elizaberta@ugr.es
}

\section{RESUMEN}

Se presenta la experiencia de un taller de Arteterapia realizado en un Centro de Día de Atención a Menores de Aldeas Infantiles SOS Granada. Su título, Jugar con trampa, pretende recoger la devolución final de uno de los participantes en el taller, que espontáneamente llegó a la conclusión de la "trampa" del arteterapia: se produce de la emergencia de algo innombrable que tiene que ser descubierto por ellos/as mismos/as y que además lleva implícito un aprendizaje.

Palabras claves: Arteterapia, Menores, Privación, Síntoma, Juego.

\section{Referencia normalizada}

AVILÉS MARTOS, M., LÓPEZ PÉREZ E. (2014). "Jugar con trampa. Taller de Arteterapia en el Centro de Día de Atención a Menores de Aldeas Infantiles SOS Granada”. En Arteterapia: Papeles de arteterapia y educación artística para la inclusión social Vol.: 9. Páginas 73-86. Madrid.

\section{SUMARIO}

Presentación; Objetivos; Características generales del colectivo; Encuadre; La experiencia del taller en dos de sus protagonistas: los casos P y L; Resultados; Conclusiones; Referencias bibliográficas.

\section{Play with trick. Art therapy workshop in the children attention centre of Aldeas Infantiles in Granada.}

\begin{abstract}
This is the experience of an art therapy workshop conducted in a Day Care Center for Children of Aldeas Infantiles SOS Granada. The title, play with trick, tries to refer to the conclusion of one of the participants in the workshop, which spontaneously arrived to the conclusion of the "trick" of art therapy: which is the result of the personal reflection that has to be discovered by themselfs with implicit learning.
\end{abstract}

Key words: Art Therapy, Children, Deprivation, Symptom, Play 


\section{CONTENTS}

1. Presentation. 2. Objetives. 3. General characteristics of the group 4. Therapeutic frame 5. Worshop experience of 2 of the participants: P and L cases. 6. Consequences 7. Conclusions.

\section{Presentación}

Esta experiencia forma parte del resultado de los talleres realizados en el Centro de Día Genil, perteneciente a Aldeas Infantiles SOS Granada, con niños y niñas en riesgo de exclusión social, y sus respectivas familias. Llevados a cabo en el contexto de las prácticas del Máster de Arteterapia y Mediación Plástica de la Universidad de Murcia, fueron realizados entre el 11 de marzo y el 8 de junio de 2013.

El enfoque humanista de Aldeas Infantiles nos facilita la intervención desde el Arteterapia y nos compromete a encontrar vínculos que la posibiliten, sin alterar la dinámica del centro. Este se nutre de la filosofía que fue configurándose desde los inicios de Aldeas Infantiles, surgiendo asimismo como respuesta a las circunstancias críticas que sufren menores, adolescentes y familias en diferentes momentos. Partiendo de una ideología paralela al nacimiento del existencialismo, y al igual que la corriente filosófica, tiene sus orígenes a partir de la devastación producida por la I Guerra Mundial, ocupándose de analizar la existencia humana, y deteniéndose a estudiar las experiencias y vivencias de las personas implicadas. Por ello, y desde una perspectiva ética existencialista, los pilares teóricos de Aldeas Infantiles entienden que el ser humano es un ser inacabado, que tendrá como tarea "llegar a ser".

El reconocimiento de estos puntos de partida nos confirma la idoneidad del contexto donde hemos desarrollado el taller. De este modo, podemos ir esbozando algunas conexiones con aspectos fundamentales que se trabajan desde el arteterapia. Partimos de que esta implica un aprendizaje desde sí mismos, con lo que vamos a trabajar ese reconocimiento de "ser en el mundo", descubriendo que somos seres inacabados, que además necesitamos el vínculo, las figuras de apego que nos ayuden a crecer para hacernos autónomos y ser capaces de emitir opiniones, reconocer emociones y deseos.

Esta exposición muestra parte del trabajo realizado, centrándose en dos de los casos más sobresalientes, P y L, hermanos gemelos cuyas circunstancias vitales pueden ser ejemplo de una de las situaciones más complejas de este colectivo.

\section{Objetivos}

De acuerdo a las necesidades que observamos en el colectivo, lo que puede aportar el taller de Arteterapia, más los objetivos que Aldeas Infantiles contempla dentro de su ideario, diseñamos un mapa de objetivos generales para el grupo que se concretan en:

- Proporcionar un espacio donde sea posible la creatividad, en un ambiente suficientemente confiable para la libre expresión y el juego. 
- Sostener, acompañar, para posibilitar una relación diferente con la realidad, que haga comprender, valorar y asumir el ser en el mundo.

- Fomentar, mediante la actividad artística, la capacidad para tomar decisiones, opinar y reflexionar acerca de sí mismos y del entorno.

- Posibilitar la creación artística como un poderoso vehículo de comunicación no verbal, que puede significar por sí mismo así como servir de puente hacia la palabra.

- Visibilizar y constatar que la creación artística dentro de un taller de arteterapia puede ser posible agente de intervención terapéutica, partiendo desde el proceso creador, la relación con el objeto artístico y los vínculos.

Junto los profesionales del centro, nos planteamos los objetivos específicos para $\mathrm{P}$ y L, unos de los casos que nos presentan como más urgentes. Estos objetivos se van a centrar en:

Fomentar en ellos mediante el proceso artístico la posibilidad de cohesionar su pensamiento para construir un discurso.

Facilitar la comunicación y la relación con los otros mediante la producción artística y el juego.

Procurar que la actividad artística sea un vehículo canalizador para sus expresiones violentas.

\section{Características generales del colectivo}

Las realidades de los niños y niñas con los que hemos trabajado tienen aspectos comunes. Encontramos que todos/as ellos/as provienen de familias desestructuradas, en las que normalmente van a vivir con la madre, en su propia casa o en la de los abuelos maternos, y con algún hermano. La mayor parte de estas estructuras familiares parecen ser el resultado de una separación. En cualquier caso, en las familias de los/as participantes hay un patrón casi general de un padre ausente o prácticamente ausente. En la realidad del taller se ha puesto de manifiesto estas ausencias, que pasan a ser simbólicas: el padre no aparece, como si no existiera, o quizás lo hace plásticamente de manera camuflada, y queda oculto en el discurso verbal.

La problemática psíquica del abandono ha sido una constante casi en todos/as ellos/as.

En determinados casos, algunos de estos niños han dado muestras de haber presenciado situaciones violentas, con posibilidad de haber sido abusados. Las circunstancias vitales de los/as participantes del taller, a menudo las hemos conocido de manera sesgada, o bien no con demasiado detalle. Aunque es complicado conocer con cierta profundidad estas situaciones, hay indicadores inestimables de estas problemáticas.

Para el psicoanálisis, la sintomatología se muestra como una producción del inconsciente. Son procesos psíquicos que se quedan interrumpidos en su viaje hacia la consciencia, y obligados a permanecer inconscientes. Ruy Henríquez afirma: 
"El síntoma se forma, entonces, como sustitución de algo que no ha conseguido manifestarse a la conciencia. Por esta razón, los síntomas son considerados como una especie de transacción o permuta, esto es, un proceso psíquico inconsciente que logra su acceso a la conciencia a cambio de deformarse hasta el punto de resultar irreconocible".(Ruy Henríquez, 2009, 2)

Esa deformación de la que nos habla Henríquez se configura como una modificación somática o una adaptación. Esto es interesante porque nos ayudará a verlo como una solución, y no, como un trastorno fácil de ser reductible.

\section{Encuadre}

El encuadre se comienza a generar en el inicio de la primera sesión, donde establecemos las reglas básicas del proceso de Arteterapia que se fundamentan en el establecimiento de unos límites en términos de respeto, referido al espacio, la temporalización, los roles y la tarea.

Se les explica que este será un espacio seguro en el cual tendrán absoluta libertad para expresar sus emociones y sus pensamientos, con la suficiente intimidad para que puedan hacerlo desde la libertad. Este espacio simbólico se ubica en un espacio físico que también hay que cuidar. Así, desde la primera sesión tratamos de hacerles no sólo partícipes sino generadores del taller.

En cuanto a la temporalización, dadas las características del grupo y las demandas del centro, disponemos dos talleres que se desarrollan desde el 11 de marzo al 8 de junio de 2013. Uno tendrá lugar con el grupo de niños/as en una sesión semanal de dos horas de duración, y el otro, quincenalmente con estos y sus madres, de tres horas, destinados a reforzar los vínculos y fomentar la interacción, a fin de explorar la posibilidad de imaginarios colectivos que inunden de esperanza sus vidas y aminoren la privación social que en la mayoría de los casos los identifican.

El encuadre temporal para todas estas sesiones va a seguir la siguiente estructura:

Planteamiento de la sesión: primeros quince minutos

Desarrollo: una hora

Turno de palabra y cierre: cuarenta y cinco minutos

En el centro, nuestro rol como arteterapeutas confluye con el de los educadores. Sin embargo, nuestra labor no ha sido la reconducción de determinadas conductas sino generar un vínculo acompañante de sus procesos de autoconciencia, manteniendo una escucha sensible para habilitar condiciones facilitadoras para cada uno/a. 
En cuanto a la tarea, nuestra labor ha sido ofrecer el material y un punto de partida como detonantes de experimentación, de juego, de reflexión, de abreacción1, mediante las siguientes propuestas:

Trabajar a partir de la inicial del nombre. Materiales: folios, ceras, lápices y rotuladores.

Construir una imagen a partir de recortes de revistas. Materiales: revistas, folios, ceras, lápices, pintura acrílica y rotuladores.

Pintar un recuerdo feliz. Materiales: papel A3, folios, ceras, lápices, pintura acrílica y rotuladores.

Construcción de una mascota o animal de compañía. Materiales: plastilina, estropajos, lanas, plumas, ojos adhesivos, algodones, rulos para el pelo, etc

Construir un vehículo para ir al lugar que se quiera. Materiales: (de reciclaje) cajas de cartón, rulos de cartón, botes de plástico, tapaderas, tetrabriks, cuerdas, papel pinocho, plumas, cinta adhesiva, etc.

Generar un espacio al que se puede ir, o desde el que se puede partir, con el vehículo que han fabricado en la sesión anterior. Materiales: (de reciclaje) cajas de cartón, rulos de cartón, botes de plástico, tapaderas, tetrabriks, cuerdas, papel pinocho, plumas, cinta adhesiva, papel continuo, materiales naturales, etc.

Propuesta libre después de la escucha del deseo del grupo. Materiales: cartones brillantes, gomaespuma de purpurina, pompones de colores, pegamento de purpurina, pegatinas diversas, rotuladores, palillos de pinchitos, etc.

Creación de una marioneta. Materiales: cartones brillantes, gomaespuma de purpurina, pompones de colores, pegamento de purpurina, pegatinas diversas, rotuladores, palillos de pinchitos, calcetines de colores, pelo, etc.

Construcción de una habitación para la marioneta. Materiales: (de reciclaje) cajas de cartón, rulos de cartón, botes de plástico, tapaderas, tetrabriks, cuerdas, papel pinocho, plumas, cartulina, cinta adhesiva, papel continuo, materiales naturales, etc.

Realización de un disfraz. Materiales: bolsas de basura, papel de aluminio, papel pinocho, cuerdas, pegamento, cartulina, papeles de colores, etc

Expresar lo que ha significado el taller de arteterapia. Materiales: plastilina de color terracota

Cierre del taller: recorrido visual por todas las obras generadas y reflexión posterior por escrito.

La particularidad de estas iniciativas es que no son a priori del proceso, sino que se gestan dentro de él, en el transcurso de las sesiones y los emergentes que van surgiendo en ellas.

\footnotetext{
${ }^{1}$ Según Jean Laplanche y Jean-Bertrand Pontalis, el concepto de abreacción se refiere a la "descarga emocional, por medio de la cual un individuo se libera del afecto ligado al recuerdo de un acontecimiento traumático, lo que evita que este se convierta en patógeno o siga siéndolo". (Laplanche y Pontalis, 1994, 1).
} 


\section{La experiencia del taller en dos de sus protagonistas: los casos $\mathbf{P}$ y $\mathbf{L}$.}

Los profesionales del centro, al comienzo de la experiencia, nos informan pormenorizadamente de las características de cada caso y de los objetivos que se plantean desde la institución. Cuando nos presentan a P y L lo hacen de manera conjunta e indiferenciada, quizás por tratarse de hermanos gemelos. Nos sugieren la posibilidad de que padezcan TDAH (Trastornos de déficit de la atención e hiperactividad) pero se da la circunstancia de que no están diagnosticados. En concreto, su historia, compartida porque son hermanos gemelos, es una trama complicada que incluye separaciones de la madre biológica, estancias en instituciones y en régimen de acogida. Y una adopción: su situación actual y relativamente reciente.

P y L van a participar activamente en la serie de propuestas que se plantean. Hacemos un recorrido por sus procesos y algunas de sus manifestaciones más sobresalientes.

$\mathrm{P}$ va a asistir a todas las sesiones excepto una. En la primera se presenta con estas palabras, con lo que va a ser su estilo habitual de discurso:

"Soy $\mathrm{P}$ (nombre y apellidos). Tengo 7 años. Me gusta jugar mucho al fútbol. No, tengo 11 años. No, tengo 8 años. Me gusta mucho, mucho, que no sé seño, estar en el váter. Me gusta Aladino, pasar el tiempo con mis amigos haciendo tonterías. Me gusta dar puñetazos a $\mathrm{C}$ en la boca, tirar de la oreja a F. Hacer deberes (el grupo se ríe y duda). Él da un golpe en la mesa y luego añade: Me gusta mucho el pelo de A, ponerme el abrigo por la noche, buscar bichos, ir a Torremolinos y jugar con los cocodrilos. Me gusta mucho leer y que los Reyes me traigan juguetes. Estar en la cama."

Todo esto es expresado con una prisa inusitada, no dejando el protagonismo del momento a otro, por más que el grupo intenta detenerle. Entre las frases, y mientras piensa qué va a decir a continuación, emite un sonido continuo. $\mathrm{Su}$ lenguaje corporal es similar a su manera de hablar. No para de balancearse constantemente, haciendo apenas equilibrios en la silla. Habla de continuo e interrumpe a quien replique. Parpadea, gestualiza y hace ademanes teatralizados: como si pegara algunas veces, da golpes en la mesa. Derrocha imaginación y verborrea. Cuando hablamos de que en el taller vamos a trabajar con las emociones, él pregunta si se puede trabajar con las "rabietas".

Su trabajo y su forma de hacer son caóticos, como si necesitara trabajar plásticamente del mismo modo que habla o deambula sobre su silla y fuera de ella. También es sorprendente su revelación de que "le gusta que le peguen". Con frecuencia aparece en sus producciones el personaje "kirogallo cantabrico" con el que se identifica en actuaciones compartidas con su hermano, en las que gesticulan con movimientos repetitivos.

El discurso de $\mathrm{P}$ resulta interesante por el derroche de información que despliega, resultando como un caleidoscopio, con una multiplicidad de piezas que se mueven sin parar generando posibles estructuras de sentido, que se invalidan las unas a las otras, por la vertiginosidad con la que se suceden en el tiempo. Al 
menos en su obra plástica, en la que esta multiplicidad queda registrada, sí que es posible ver todo a la vez.

En la penúltima sesión, ante la propuesta de trabajar con el significado del arteterapia construye un personaje, con apéndice y explica que son "tubos para defecar, orinar y respirar".

$\mathrm{L}$ se presenta diciendo:

"Me gusta la pelota. Me han dicho que vengo a divertirme. Mi animal preferido, no sé si decirlo, es la mofeta. Me gusta estar en Caniles, porque se está muy fresquito, como helados, estoy en manga corta. Tengo otro animal preferido: la anaconda. Me gusta el baloncesto, pero el fútbol mucho más."

En una de las primeras sesiones surge el tema de las emociones. L dice que "las emociones son cosas que te ayudan a estar en la vida, a estar delante"; a lo que añade: "Me gusta hacer el kirogallo cantabrico. ¿Puedo hacerlo otra vez?" Entonces escenifica este personaje.

L mantiene una actitud intermitente entre la calma y la agitación de unas sesiones a otras. En ocasiones se golpea la cabeza con fuerza y manifiesta que le gusta molestar, que es lo que más le gusta y que le peguen. Las manifestaciones verbales de $\mathrm{L}$ en una sesión en particular tienen un componente de índole sexual y de violencia. Sin embargo, en otros momentos recuerda a su madre, manifestando el deseo de regalarle las producciones que elabora en el taller y dedicándole por escrito algunos de estos trabajos, manifestando en ellos cuánto le quiere.

Recordemos que la madre actual de los niños es adoptiva, que fueron separados de su madre biológica en varias ocasiones y pasaron por la experiencia de ser separados en distintos centros de acogida. Como afirma Dolto, (1997) la separación de la madre en niños de corta edad, y la posterior inclusión en otro entorno, viene a ser como el trasplante de un vegetal; como una ruptura que da lugar a un nuevo nacimiento traumático. Esto puede dejar, según la autora, un recuerdo de "vida fetal prolongada", algo que nos parece observar en los hermanos desde el primer momento.

En efecto, parecen enredados aún en un estado de no individuación, confundidos entre ellos y con el entorno, del que no saben distinguirse y que se vuelca en sus producciones con formas fluidas, dispersas y caóticas, de la misma manera que elaboran su discurso.

Tanto en su expresión verbal como en su expresión plástica se va poner de manifiesto esta indefinición de límites entre ambos niños. Su manera de estar en el taller es igualmente convulsa, pasándose el testigo con frecuencia y adoptando el uno las maneras del otro, dentro de la misma sesión.

Resultados

Nuestra herramienta ha sido la observación. Es común que ante la circunstancia de observar o tratar a hermanos gemelos de manera cotidiana, haya que poner cuidado en hacerlo por separado y también juntos. El proceso termina por dibujar dos subjetividades que, sin embargo, comparten un mismo universo simbólico. 


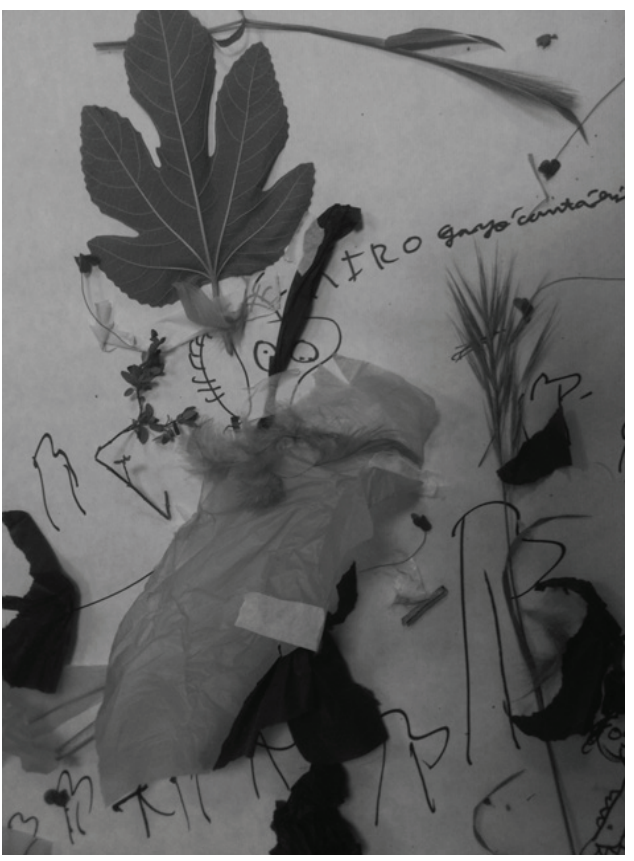

Fig. 1 Kirogallo cantábrico pintado por $\mathrm{P}$

Dentro de este universo cobra un protagonismo fundamental un personaje que sale en su verborrea continua, 2 situándose a medio camino entre el objeto interno $y$ objeto externo, como un auténtico objeto transicional, tal y como postula Donald W. Winnicott (1982), que quizás los conecta de forma remota con un entorno seguro. Llamándolo el "kirogallo cantabrico", nos lo han presentado desde el principio de la experiencia del taller de forma dramatizada, utilizando sus propios cuerpos. El kirogallo durante el proceso pasa a ser una producción artística que pueden tocar y con la que pueden jugar, sirviendo de vehículo para canalizar los impulsos agresivos que desestabilizan su relación con los demás.

La tarea de distinguirlos ha resultado difícil pues la conducta de uno se contagiaba hacia el otro y viceversa. La agitación de sus cuerpos deambulando continuamente por la sala, debajo de la mesa, sobre las sillas, sobre los compañeros es una vorágine que se manifiesta también en el encuentro con la materia pictórica. Es el mismo movimiento que bate la pintura en los platos, derramándola por todo su entorno, como si fuera sus propios cuerpos, su propia materia orgánica que se desborda continuamente quizás por esa necesidad de expulsar su dolor, o su historia.

Sin embargo, en el transcurso del proceso y las producciones plásticas y verbales, sí que vamos encontrando diferencias. P se muestra más autónomo, con mayor capacidad de abordaje y resolución con los materiales y la idea, además de un pensamiento más estructurado que hace que sus obras tengan un carácter más ordenado. Sin embargo, L se entrega más al garabato, jugando a dejarse llevar, y

\footnotetext{
${ }^{2}$ El kirogallo cantabrico es un personaje que resulta muy curioso, porque ambos hermanos lo escenifican con mucha frecuencia, poniendo una de sus manos a modo de cresta sobre la cabeza, los carrillos inflados y la boca encogida, al tiempo que sus pupilas deambulan sin posarse en ningún lugar. Su nombre parece derivarse del urogallo cantábrico, ave en extinción que habita en la cordillera cantábrica. (http://www.urogallocantabrico.com)

Ellos no explican su origen, aunque hemos podido observar que su madre intenta detenerlos suavemente cuando juegan a esto.
} 
con un deseo constante de vincular su producción al amor a la madre, como si no separara su capacidad creadora del vínculo.

La no contención, probablemente entre otros factores, genera en P y L una actitud cargada de cierta violencia hacia los otros/as participantes y hacia ellos mismos. Es posible que para todos/as, el miedo y la desesperanza estén en la base de la respuesta agresiva. Winnicott (2007) nos aclara que esta no tiene por qué ser del todo evidente, sino que la agresividad se localiza en diferentes lugares. Puede manifestarse de manera abierta en conductas hostiles, o bien puede volverse hacia el/la niño/a en forma reprimida. Hemos podido encontrar posibles ejemplos de esto en la conducta ambigua y la necesidad de golpear y de ser golpeados de P y L.

Al reprimir estos impulsos hay cierta inhibición de la creatividad y del desarrollo de un estilo de vida rico y espontáneo. Ante esto, Winnicott propone el juego como puente hacia la expresión:

"El juego se basa en la aceptación de símbolos y, por consiguiente, encierra posibilidades infinitas. Gracias a él, el niño puede experienciar cuanto encuentre en su realidad psíquica interior y personal, que es la base de su creciente sentido de identidad. Allí habrá amor, pero también agresión."

(D. W. Winnicott, 2007, 104)

El juego aparece como una alternativa a la destrucción. Según el autor, en su afán constructivo, integrador, va a contar con sus propios materiales, también lo que siente respecto a sí mismo. De ese modo acarreará su aceptación personal y quizás se responsabilizará de su vertiente destructiva.

Por su parte, Edith Kramer, encuentra en el proceso artístico una vía de salida y transformación de la energía que los/as niños/as derrochan en sus impulsos hostiles:

"El terapeuta, al ayudar a los chicos a llevar a cabo sus trabajos, encuentra las tendencias agresivas como contenido emocional de sus pinturas, como fuerza destructiva que inhibe y distorsiona el proceso creativo, o, bajo una forma sublimada, como energía constructiva. A menudo estos tres factores intervienen en una misma obra pictórica"

(Edith Kramer, 1982, 113)

De cualquier forma, no olvidemos que una de las cuestiones que vamos a descubrir a lo largo de las sesiones es lo ambiguo de esto que, en principio, parece ser conducta hostil y agresiva. Hemos podido descubrir que, además de la posibilidad de la que nos habla Kramer, hay una dimensión que también hay que tener en cuenta: el cuerpo tiene un modo propio de comunicación, no reductible a palabras, que cambia según los contextos. Sue Jennings, desde su enfoque del cuerpo, habla de la confusión que producen los gestos cuando no se tiene en cuenta el contexto. 


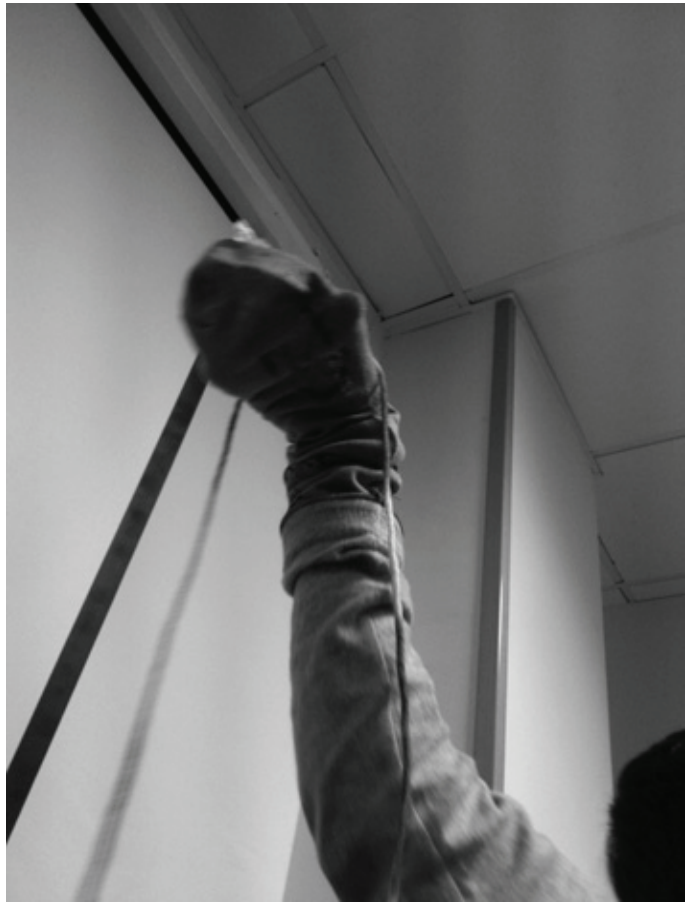

Fig. 2 Elaborada por P
"Lo que es una amistosa comunicación, puede ser considerado "violento y agresivo" por el observador que no comprende ese lenguaje específico del cuerpo"

(Sue Jennings, 1979, 34)

No se trata de desoír las desavenencias que pueden elaborarse en la trama de relaciones, ni de dejar que se maltraten impunemente, pero tampoco atribuirles un solo sentido que pase únicamente por la mirada adulta, que puede estar algo ajena a los códigos específicos del colectivo.

Por otro lado, neutralizar este tipo de acciones puede ser que coarte o detenga el esfuerzo que algunos participantes intentan hacer para explicarse su propio material inconsciente. La obstinación de $\mathrm{P}$ y $\mathrm{L}$ en intentar ser golpeados, en un estilo repetitivo de acting out, y su posible derivado en el recurrente kirogallo, parecen igualmente intentos de resolver algo que no recuerdan y que pretenden comprender a fuerza de repetir. Sostener estas escenas va a ser crucial para hacer posible los procesos de estos y otros niños.

Todo esto nos hace pensar en la idoneidad del taller de arteterapia como un lugar de experiencias en el que se pueden integrar de manera saludable y en un entorno seguro, tanto la destrucción como ese afán constructivo. Sobre todo, porque en esa posibilidad, se ofrece a los niños y niñas participantes, la ocasión de reparar lo dañado. Dice al respecto Melanie Klein:

"En los análisis de niños, cuando la representación de deseos destructivos es seguida de la expresión de tendencias reactivas, encontramos constantemente que el dibujo y la pintura son utilizados como medios de reparar a la gente"

(Melanie Klein, 2006, 235)

Mediante el juego y la creatividad que proponemos desde el Arteterapia se da la oportunidad de participar en la tarea de atender sus necesidades. Además, y de 
acuerdo a las premisas teóricas e ideológicas de Aldeas Infantiles3, lo haremos desde el sostén del encuadre y el convencimiento de la importancia de favorecer el vínculo entre madres e hijos/as, para participar de su preocupación y asumir el compromiso como arteterapeutas.

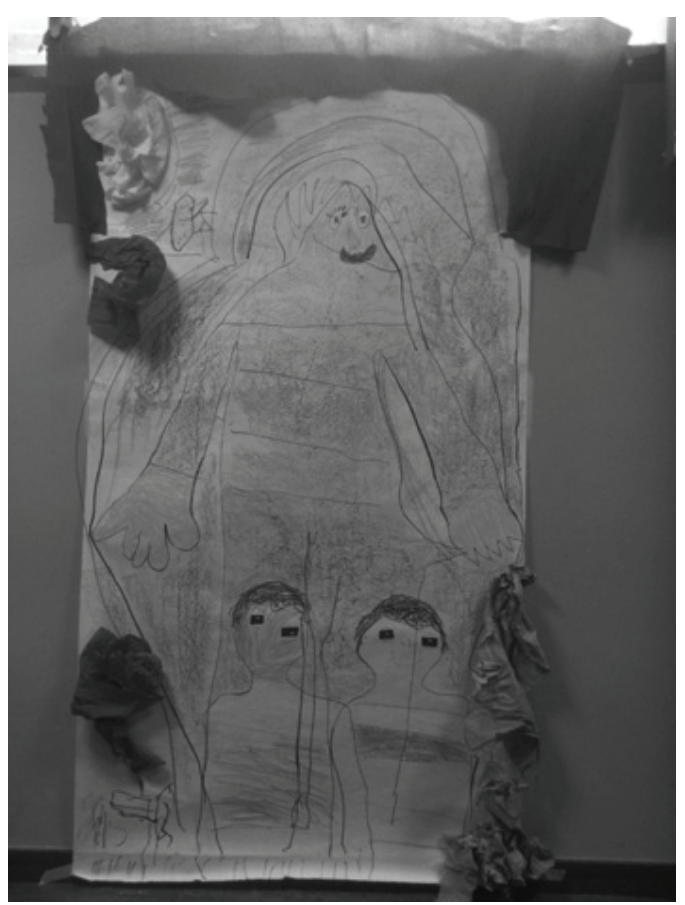

Fig. 3 Elaborada por P, L y su madre

Hemos podido constatar que lo que aparentemente puede parecer signo de trastorno, resulta un horizonte esperanzador. Nos referimos a la sugerencia inicial desde la institución de un posible diagnóstico de TDAH y por tanto, una posible sintomatología, para $\mathrm{P}$ y L. Pero en nuestro taller, más que síntomas hemos visto señales; es la observación cotidiana del material emocional que se hace tangible en el proceso lo que nos hace reparar en estos detalles que empiezan a llamar nuestra atención. Además, desde una postura ética, no podemos hablar directamente de síntomas, pues no nos corresponde hacer diagnósticos.

En este sentido, hemos podido observar un amplio abanico de señales que se manifiestan en los niños, a las que, sin embargo, podemos darles el valor que Jorge Sosa (2008) atribuye a los síntomas: son ruídos que sobresalen del sonido habitual y nos avisan. Pérdida de control, inseguridad, falta de identidad, agresividad, conducta alterada, falta de atención, dificultad de expresar emociones, incapacidad para resolver conflictos, lenguaje disgregado, impulsividad, inadaptación social, dificultad para ponerse en el lugar del otro, dificultad para la reflexión. Quizás en la base de todo ello esté la angustia, "el afecto que no engaña" y es

\footnotetext{
${ }^{3}$ La primera Aldea Infantil S.O.S. fue fundada por Herman Gmeiner que en 1949, en Austria, advierte la posibilidad de generar nuevos hogares para niños huérfanos y mujeres que había perdido a sus familias en la guerra, con el propósito de recrear el ambiente familiar del que habían sido desposeídos. Esta es la filosofía de la que parte Aldeas Infantiles.
} 
"signo de la inminencia de lo real", como lo cita Enrique Pastrana4, (2004) parafraseando a Lacan. Avisa que no hay que adormecerla sino dosificarla, pues sin ella no hay posibilidad de análisis. Paralelamente en nuestro terreno, aparece en todas estas formas y es una señal saludable, en cierto modo, ya que significa la posibilidad de elaboración.

Al finalizar nuestra experiencia, nos encontramos con una sorpresa. Las madres piden al centro un encuentro con nosotras como devolución, para "saber qué hemos visto en sus hijos/as". ¿Qué se desprende de pedirnos devolución? Esto nos constata que se ha creado una expectativa abierta en ellas, que ha permitido una dinámica especular y ha movilizado la transferencia de los procesos arteterapéuticos a sus vidas. Quizás piensen que puedan así redescubrir y reinaugurar la relación con sus hijos/as, y con esto la de ellas consigo mismas. No olvidemos que ya traían esa esperanza al taller, cuando trajeron a sus hijos. Pero este ha sido suficientemente confiable para merecer su esperanza y han visto más próximo ese horizonte.

\section{Conclusiones}

Repasamos la experiencia y nos detenemos en sus instantes, a veces de manera explícita a través de las revelaciones verbales; otras con su lenguaje corporal, con sus silencios, con su agitación, sus gritos, la agresividad, el juego. Atravesamos estas vivencias de nuevo en la revisión de sus procesos creadores, y en sus obras particulares, y entonces podemos constatar los efectos favorables del taller y de lo ocurrido en él, que se precisan en los siguientes aspectos:

- Del hacer lo que pienso a pensar lo que hago.

En las primeras sesiones aparecen enfrentamientos verbales y corporales cargados de agresividad. Esa resistencia empieza a aminorar, pero no desaparece sino que progresivamente se va a ir volcando en el acto creativo.

- Del impulso a la voluntad significante.

La energía que se volcaba en las primeras sesiones, tanto en las obras como en sus palabras y gestos corporales se ha ido catalizando a través del juego. Pero el propio juego, contenido en la propuesta, revela sus posibilidades metaforizantes, con lo que sus capacidades expresivas encuentran el lugar idóneo para dotar de sentido.

- Del pensamiento único a la ampliación del sentido de las cosas

\footnotetext{
4 "La angustia, el afecto que no engaña" es un capítulo de la obra contenida en la bibliografía: Slimobich, J. L., Cruz, F., Duro, M., Levy, B. (2004) Lacan: amor y deseo en la civilización del odio. Granada: Universidad de Granada
} 
El acto de pegarse adquiere una significación diferente porque pegarse puede ser también pegarse a otro. En el taller se posibilita pensar esta violencia, para resignificarla, porque el encuadre la deja fluir hasta que se va depositando en las propuestas, y ya no se necesita tanto inscribir la huella física en los cuerpos sino sobre los materiales.

- Del miedo en "soledad"a la posibilidad de sentirse acompañados

A pesar de no poder evitar el sufrimiento de las circunstancias vitales de $\mathrm{P}$ y $\mathrm{L}$, el trabajo del taller ha hecho posible un acompañamiento, generando lazos sostenedores, la expresión de afectos y tal vez restablecer el curso de un desarrollo saludable.

- De estar fuera a estar dentro: el valor de la transferencia

El grupo será quien nos otorgue un lugar dentro del proceso. El encuadre pasa de ser un marco estático a otro flexible y dinámico. Esto posibilita un cambio de perspectiva también en nosotras. Eso es el punto de partida preciso de un trabajo de campo que nos ha procurado una gran cantidad de material gráfico, verbal y no verbal nacido de la relación intersubjetiva de la que hemos formado parte.

- De la emoción latente a la emoción manifiesta

En general, de la latencia de estas emociones se ha pasado a una mayor visibilidad. El proceso ha posibilitado un acto de comunicación consigo mismos/as, propiciando paso a paso un progresivo auto-reconocimiento.

Como reflexión final recogemos la verbalización de $\mathrm{L}$ en la despedida del taller, que nos parece una buena definición de arteterapia:

"Esto del Arteterapia tiene trampa, porque aprendemos algo que no sabemos lo que es, que vosotras no nos decís, que lo tenemos que descubrir nosotros."

\section{Referencias bibliográficas}

DOLTO, F. (1997) La imagen inconsciente del cuerpo. Barcelona, Paidós

FIORINI, H. (1995) El psiquismo creador. Buenos Aires, Paidós

FREUD, A. (2006) Obras escogidas. Barcelona, RBA

KRAMER, E. (1982) Terapia a través del arte en una comunidad infantil. Buenos Aire, Kapelusz

JENNINGS, S (1979) Terapia creativa. Buenos Aires, Kapelusz

RODULFO, M. (1999) El niño del dibujo. Buenos Aires, Paidós

WINNICOTT, D. (2007) Deprivación y delincuencia. Madrid, RBA

WINNICOTT, D. (1982). Realidad y juego. Barcelona, Gedisa 
Documentación en la red:

HENRÍQUEZ, R. (2009). El sentido de los síntomas.

www.ruyhenriquez.com/doc/conferencias/nsafrica2009.pdf (consultado el 30/03/2014)

SOSA, J (2008) « Del síntoma y sus paradojas ». L'interrogant. Revista de la Fundació Nou Barris per a la Salut Mental (Barcelona) Vol 8

http://www.revistainterrogant.org/?page_id=175 (consultado el 29/09/2014) 